\title{
Neonatal Nutrition and Later Outcomes of Very Low Birth Weight and Preterm Infants $<32$ Gestational Age at a Tertiary Care Hospital of Portugal
}

\author{
Conceição Costa ${ }^{1 *}$, Teresa Torres ${ }^{1}$, Andreia Teles $^{2}$ \\ ${ }^{1}$ Departments of Pediatrics-Centro Hospitalar Vila Nova de Gaia/Espinho, Vila Nova de Gaia, Portugal \\ ${ }^{2}$ Departments of Pediatrics, Neonatology Unit-Centro Hospitalar Vila Nova de Gaia/Espinho, Vila Nova de \\ Gaia, Portugal \\ Email:
}

Received 19 June 2015; accepted 23 August 2015; published 26 August 2015

Copyright (C) 2015 by authors and Scientific Research Publishing Inc.

This work is licensed under the Creative Commons Attribution International License (CC BY).

http://creativecommons.org/licenses/by/4.0/

(c) (i) Open Access

\begin{abstract}
Premature infants, especially those born with less than $1500 \mathrm{~g}$, often exhibit slow overall growth. Lack of early nutritional support is an important element. The present authors describe parenteral nutritional practices in a tertiary hospital and evaluate postnatal growth of preterm infants under 32 weeks of gestational age or with a birth weight $<1500$ g. For population study, we examined 431 newborn files. Their median gestational age was 29.7 weeks. Of them, $25.4 \%$ were small for gestational age (SGA). $77.5 \%$ received parenteral nutrition (PN), $54.5 \%$ of which was provided on the first day. The average time was 14.7 days. The average weight gain by the $30^{\text {th }}$ day was $425 \mathrm{~g}$. At discharge, $37 \%$ were $<\mathrm{P} 3$ and $26 \%$ were P3 - P10. By the $3^{\text {rd }}$ month $20 \%$ had their weight under P3, decreasing to $10 \%$ by the $12^{\text {th }}$ month. Children who initiated PN in the first 24 hours of life had significantly better weight on the $30^{\text {th }}$ day of their life $(p<0.001)$ and in the $6^{\text {th }}$ month of corrected age $(p=0.038)$. And they had better Body Mass Index (BMI) in the $3^{\text {rd }}(p=$ $0.012)$ and $12^{\text {th }}(p=0.023)$ months. Despite better feeding practices, there is still significant failure in post natal growth. Early introduction of PN was associated with an improved weight gain, which suggests that nutrition that included amino acids may be critical during the first 24 hours of life.
\end{abstract}

\section{Keywords}

Growth, Parenteral Nutrition, Preterm Infant, Very Low Birth Weight

\footnotetext{
${ }^{*}$ Corresponding author.
} 


\section{Introduction}

Feeding preterm infants is a challenge because there is still much to learn. And nutrition is often limited by the management of the clinical problems of extreme prematurity. Although great efforts have been made to improve neonatal nutrition in very low birth weight (VLBW) infants, many do not receive adequate nutrient intake and thus develop extrauterine growth restriction. Parenteral nutrition (PN), which allows the infant's requirements for growth and development to be met, is indicated in infants for whom feeding via the enteral route is impossible, inadequate, or hazardous. Despite some recommendations, insufficient alimentation and postnatal growth restriction are still frequently observed these days [1].

Extensive research has established that infants with very low birth weight (VLBW) are particularly vulnerable to the effects of early nutritional deficiencies. Any insufficiency or delay in early nutritional support may be deleterious and contribute to both postnatal morbidities and impaired neurodevelopmental outcomes [2]. So a premature birth is a nutritional emergency!

The goal of nutrient supply for preterm infants is to achieve a pattern of growth that is similar to intra-uterine pattern [3]. The achievement of a postnatal growth at a rate approximating that of the third trimester of intrauterine life is considered the best means to facilitate later growth and development [2]-[4].

The history of neonatal feeding practices has undergone many modifications. In the last few years, great attention has been given to high amino acid supply in VLBW infants from the first day of life in order to avoid catabolism, establish anabolism, achieve in utero protein accretion rates, and promote linear growth. Current scientific evidence highlights the importance of supplementing the premature infant with sufficient nutrients not only to improve survival, growth and neurological development, but also to secure future health and quality of life [4] [5].

Although the association of an early PN and better growth in the first weeks of life has been studied by some authors, few studies report this benefit during the first year of life.

\section{Objectives}

The primary objectives were to describe alimentation of neonatal nutrition in a neonatal intensive unit in the last eleven years and determine the association between neonatal parenteral nutritional practices and infants' growth in the first year of life.

\section{Material and Methods}

We performed a retrospective cohort study. Our data were collected based on clinical records of infants admitted to the Neonatal Unit at a Tertiary Care Hospital of Portugal between January 2002 and December 2012 with less than 32 weeks of gestational age or birth weight less than $1500 \mathrm{~g}$.

The data for each eligible infant were retrospectively collected. They include gender, birth, gestational age, hospitalization diagnosis, days with PN, PN start day, PN composition (proteins, lipids and carbohydrates) on the $1^{\text {st }}$ day and maximum rate. Gestational age was based on obstetrical ultrasound; intrauterine growth restriction (IUGR) was considered if birth weight under P10. Weighing was routinely performed by nurses with digital electronic scales (reading to at least the nearest $10 \mathrm{~g}$ ). Percentiles and Z-scores of growth were determined using Fenton and Kim curves of 2013 and growth curves from WHO 2006.

Statistical analysis was done using SPSS 20.0. Categorical variables were analyzed by using $\chi^{2}$ for independent measures. Students' $t$ test was used for continuous variables. $\mathrm{P}$ values of $<0.05$ were considered significant and confidence interval of $95 \%$ was used.

Permission to conduct the study was granted by the Hospital Ethics Committee.

\section{Results}

The study consisted 431 preterm infants admitted to the Neonatal Department between January 2002 and December 2012 with less than 32 weeks of gestational age or birth weight less than $1500 \mathrm{~g}$. Baseline characteristics of the entire study population are displayed in Table 1 . The median birth weight was $1216 \mathrm{~g}$ and the gestation age of 29.7 weeks. Those who had suffered intrauterine growth restriction took up $24.5 \%$.

Table 2 characterizes the parenteral nutritional practices of the studied population. Of the total 431 infants, 334 (77.5\%) received PN. Of the 92 infants who haven’t received PN, 72 died and 6 were transferred to other 
Table 1. Population characteristics.

\begin{tabular}{cc}
\hline Baseline characteristics & Observation \\
\hline Median of gestational age in weeks & 29.7 \\
Infant Gender; N (\%) & $241(55.9)$ \\
Male & $190(44.1)$ \\
Female & 1216.3 \\
Median of birth weight in grams & $42(9.9)$ \\
Birth weight; N (\%) & $73(17.2)$ \\
$<750$ & $110(25.9)$ \\
$750-999$ & $143(33.6)$ \\
$1000-1249$ & $57(13.4)$ \\
& $1250-1499$ \\
\hline
\end{tabular}

${ }^{1}$ IUGR = Intrauterine Growth Restriction.

Table 2. Characterization of parenteral nutrition.

\begin{tabular}{cc}
\hline Baseline characteristics & Observation \\
\hline Total, N (\%) & $334(77.5)$ \\
Beginning, N (\%) & $182(54.5)$ \\
First 24 hours & $152(45.5)$ \\
After 24 hours & 14.7 \\
Duration, average in days & \\
Maximal doses of proteins, average in $\mathrm{g} / \mathrm{kg} /$ day & 3.3 \\
$<28$ weeks & 2.9 \\
{$[28$ - 32] weeks } & 2.7 \\
$\geq 32$ weeks & \\
Maximal doses of lipids, average in $\mathrm{g} / \mathrm{kg} / \mathrm{day}$ & 3 \\
$<28$ weeks & 2.6 \\
{$[28$ - 32] weeks } & 2.4 \\
$\geq 32$ weeks & 8.6 \\
\hline$<28$ weeks & $32]$ weeks \\
Maximal doses of glucose, average in $\mathrm{mg} / \mathrm{kg} /{ }^{\prime}$ & 7.7 \\
\hline 28 weeks & \\
\hline
\end{tabular}

hospitals during the first hours of life. Analyzing those who received PN, we found that $54.5 \%$ started during the first 24 hours. The average duration of PN was 14.7 days. The maximal dose of proteins, lipids and glucose was stratified according to gestational age.

These infants' average weight gain on the $30^{\text {th }}$ day of their life was 425 g. Stratifying their weight on day 30 to their gestational age (Figure 1), 31\% were under P3; 29\% were between P3 and P10; 36\% were between P10 and P50 and 4\% between P50-P90. By the time of discharge, the average weight had become $2014 \mathrm{~g}$ with an average duration of 36.3 weeks. Stratifying the percentiles (Figure 2), 37\% were under P3; 26\% were between 


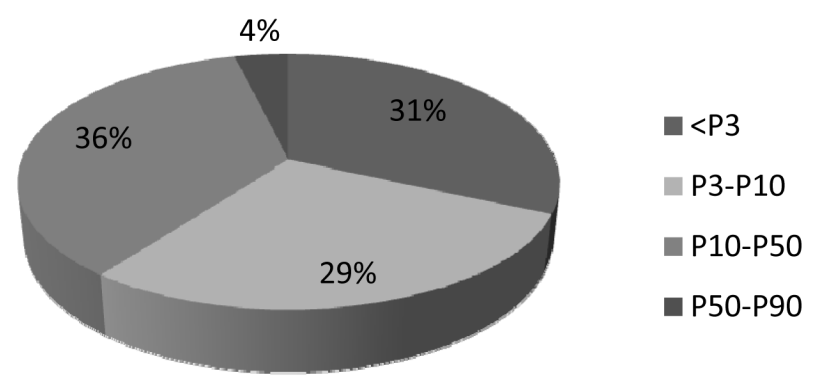

Figure 1. Weight stratified in percentiles at day 30 of life.

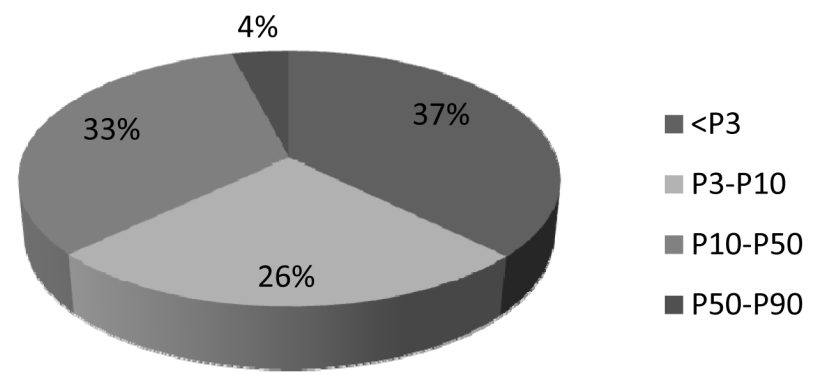

Figure 2. Weight stratified in percentiles at discharge.

P3 and P10; 33\% were between P10 and P50 and 4\% between P50 - P90.

Figure 3 and Figure 4 show the evolution of weight and Body Mass Index (BMI) of the studied population's first year of life. The percentage of infants with weight under P3 is $20 \%$ in the $3^{\text {rd }}$ month of corrected age, decreasing to $10 \%$ in the $12^{\text {th }}$ month of corrected age. The proportion of infants with BMI under P3 is $8 \%$ and $4 \%$ in the $3^{\text {rd }}$ and $12^{\text {th }}$ months of corrected age. Of these children with weight under P3 in the $12^{\text {th }}$ month, $40 \%$ were small for gestational age (SGA), and 23\% were under 28 weeks at birth.

\section{Comparing Parenteral Nutrition (PN) Started before and after the First 24 Hours of Live}

According to the objectives of the study we compared infants who started parenteral nutrition in the first 24 hours of life (Group 1: $\mathrm{N}=182$ ) with those who started parenteral nutrition after 24 hours of life (Group 2: $\mathrm{N}=$ 152). Groups like these are naturally made. It is because our institution laboratory prepares PN one time per day, so infants born after PN preparation, will only start it on the $2^{\text {nd }}$ day. Table 3 compares the baseline characteristics of the two groups of the study. No differences were found in gestational age, birth weight, and the rate of SGA.

Analyzing the maximal doses of proteins, lipids and glucose achieved in parenteral nutrition of both groups (Table 4), we found no differences between the two groups. However, beginning of PN in the first 24 hours was associated with early achievement of maximal doses of proteins (6.6 days vs 9.2 days $-p=0.002$ ), lipids (6.1 days vs 8.5 days $-\mathrm{p}=0.003$ ) and glucose (7.6 days vs 10.8 days $-\mathrm{p}=0.003$ ); and early start of enteral nutrition (2.8 days vs 3.9 days $-\mathrm{p}<0.001$ ).

The two groups under observation displayed different proportions of complications during hospitalization. Group 1, who started PN before 24 hours of life, had significantly less infants with necrotizating enterocolitis (NEC), 3.8\% vs $16.1 \%$ ( $<$ 0.001); intraventricular hemorrhage (IVH), 7.1\% vs $13.4 \%$ ( $\mathrm{p}=0.013$ ); sepsis, $25.0 \%$ vs $45.6 \%$, ( $<$ <.001) and bronchopulmonary dysplasia (BPD), 3.3\% vs $11.4 \%(\mathrm{p}=0.003)$.

Evaluating weight gain on the $30^{\text {th }}$ day of life; we found that the $1^{\text {st }}$ group was associated with better weight gain: $477 \mathrm{~g}( \pm 214)$ vs $355 \mathrm{~g}( \pm 200)-\mathrm{p}<0.001$. At discharge there were no significant differences found between the groups during our evaluation of the percentiles of weight, length and head circumference.

The follow-up during the first year of life was possible for $85 \%$ of the population submitted to PN. In the 3, 6, 9 and 12 months infants' weight, length, head circumference, and BMI were evaluated. These records were converted to Z-score for corrected age (Graphics 1-4). In all the periods under study, the weight, length, and 


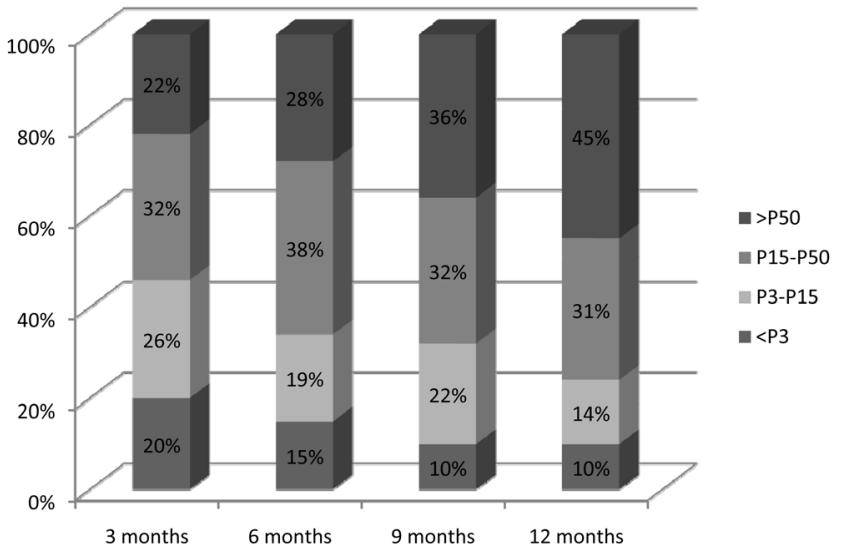

Figure 3. Weight evolution during the first year of life.

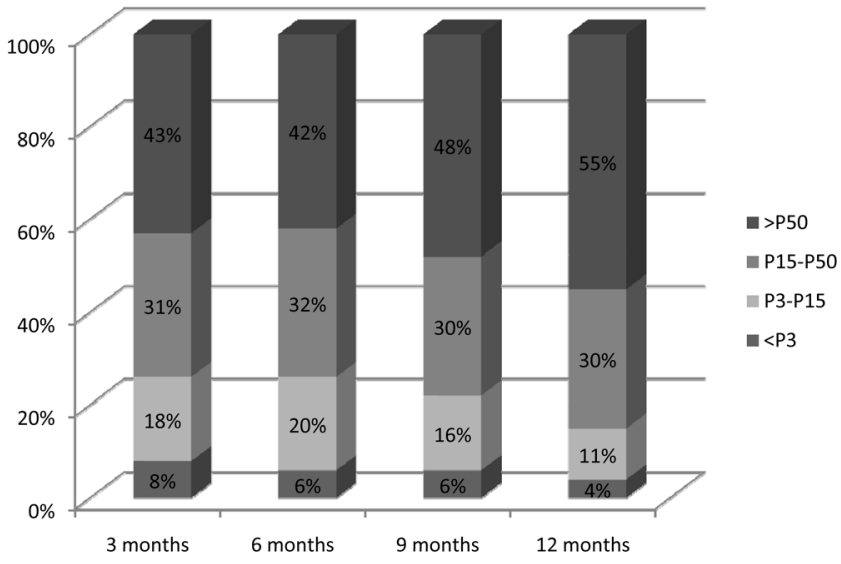

Figure 4. BMI evolution during the first year of life.

Table 3. Baseline characteristics of the two groups.

\begin{tabular}{|c|c|c|c|}
\hline & PN before 24 h & PN after $24 \mathrm{~h}$ & $\mathbf{p}$ \\
\hline Gestational age in weeks (average \pm SD) & $29.95 \pm 2.19$ & $29.50 \pm 2.50$ & 0.079 \\
\hline Birth weight in grams (average \pm SD) & $1240.97 \pm 286$ & $1188.74 \pm 306$ & 0.106 \\
\hline $\mathrm{SGA}^{1}$ rate (\%) & $25.7 \%$ & $24.5 \%$ & 0.752 \\
\hline
\end{tabular}

${ }^{1} \mathrm{SGA}=$ Small for Gestational Age.

Table 4. Differences in parenteral nutrition (maximal doses of proteins, lipids and glucose) and enteral nutrition between two groups.

\begin{tabular}{cccc}
\hline & PN before $24 \mathrm{~h}$ & PN after $24 \mathrm{~h}$ & $\mathrm{p}$ \\
\hline Maximal dose of proteins $(\mathrm{g} / \mathrm{kg} / \mathrm{d})$ & $2.77 \pm 0.52$ & $2.74 \pm 0.71$ & 0.726 \\
Day of maximal dose & $6.6 \pm 5.2$ & $9.2 \pm 9.0$ & 0.002 \\
Maximal dose of lipids $(\mathrm{g} / \mathrm{kg} / \mathrm{d})$ & $2.61 \pm 0.55$ & $2.64 \pm 0.54$ & 0.593 \\
Day of maximal dose & $6.13 \pm 4.4$ & $8.53 \pm 7.9$ & 0.003 \\
Maximal dose of glucose $\left(\mathrm{mg} / \mathrm{kg} /{ }^{\prime}\right)$ & $8.47 \pm 4.9$ & $8.38 \pm 1.9$ & 0.838 \\
Beginning of enteral nutrition & $7.6 \pm 6.4$ & $10.8 \pm 7.8$ & 0.003 \\
Day of exclusively enteral nutrition & $2.76 \pm 1.3$ & $3.9 \pm 3.4$ & $<0.001$ \\
\hline
\end{tabular}




\section{Weight}

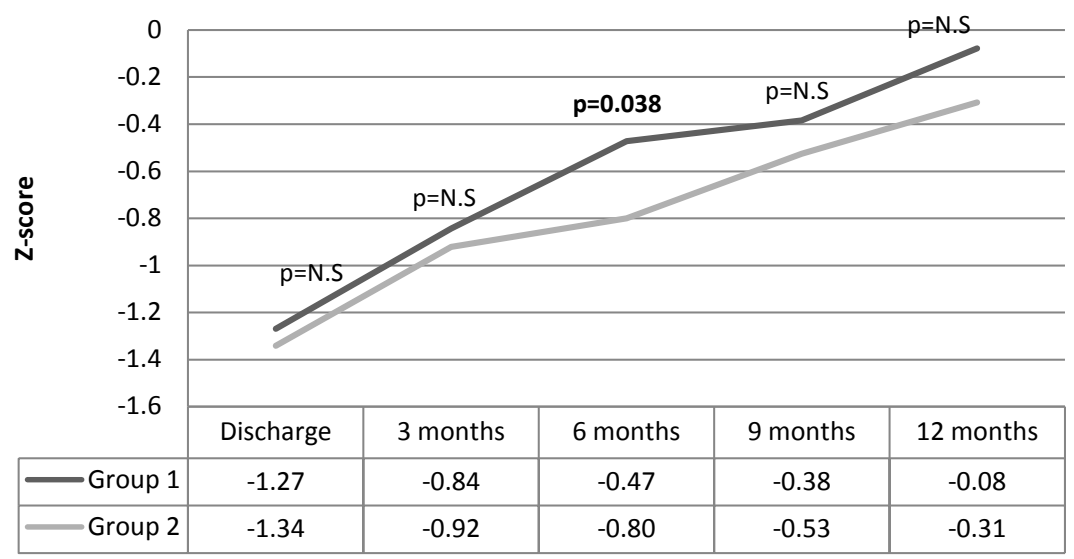

Graphic 1. Average weight $\mathrm{z}$ score change in the two groups from discharge to 12 months.

\section{Length}

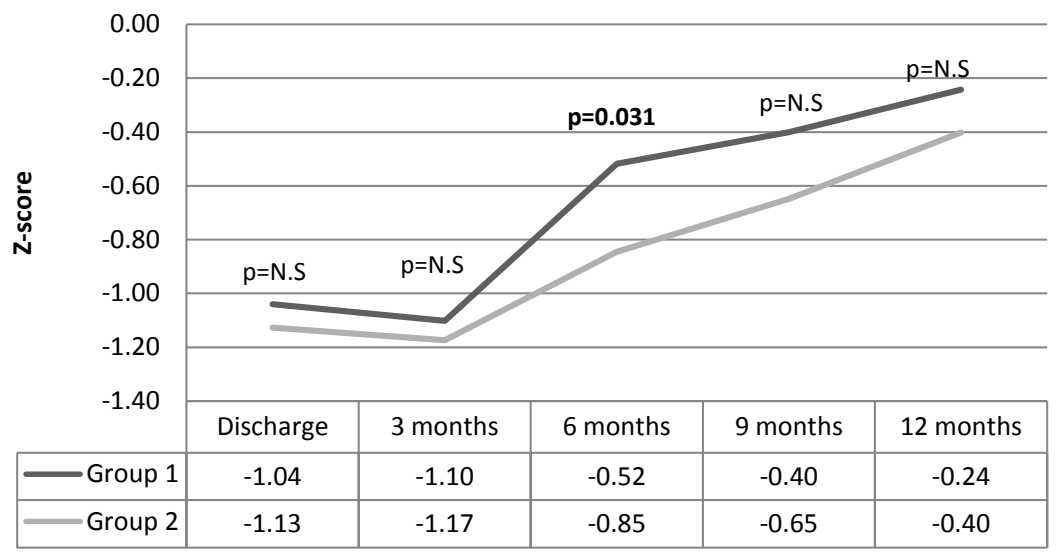

Graphic 2. Average length $\mathrm{z}$ score change in the two groups from discharge to 12 months.

\section{Head circumference}

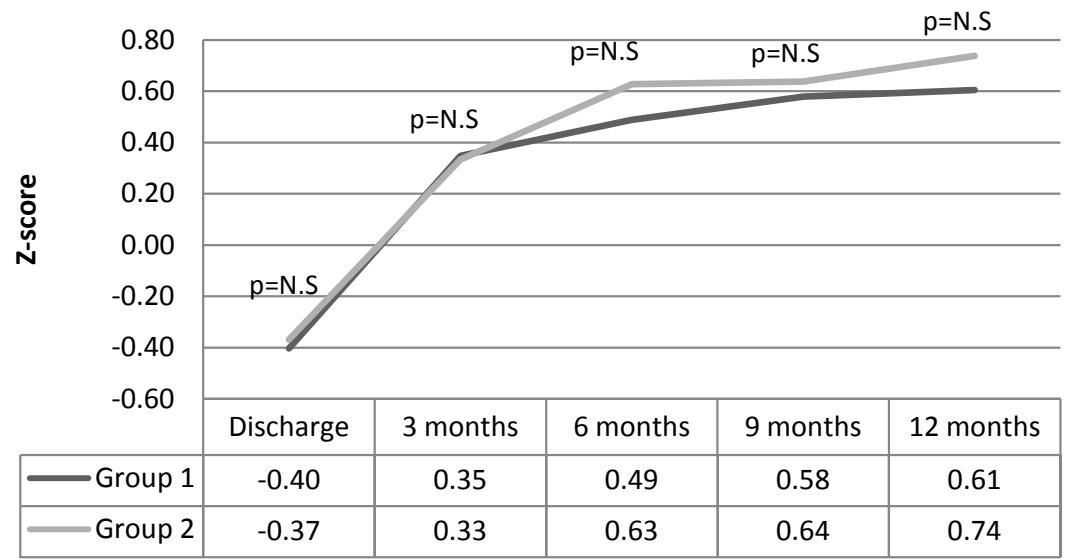

Graphic 3. Average head circumference $\mathrm{z}$ score change in the two groups from discharge to 12 months. 


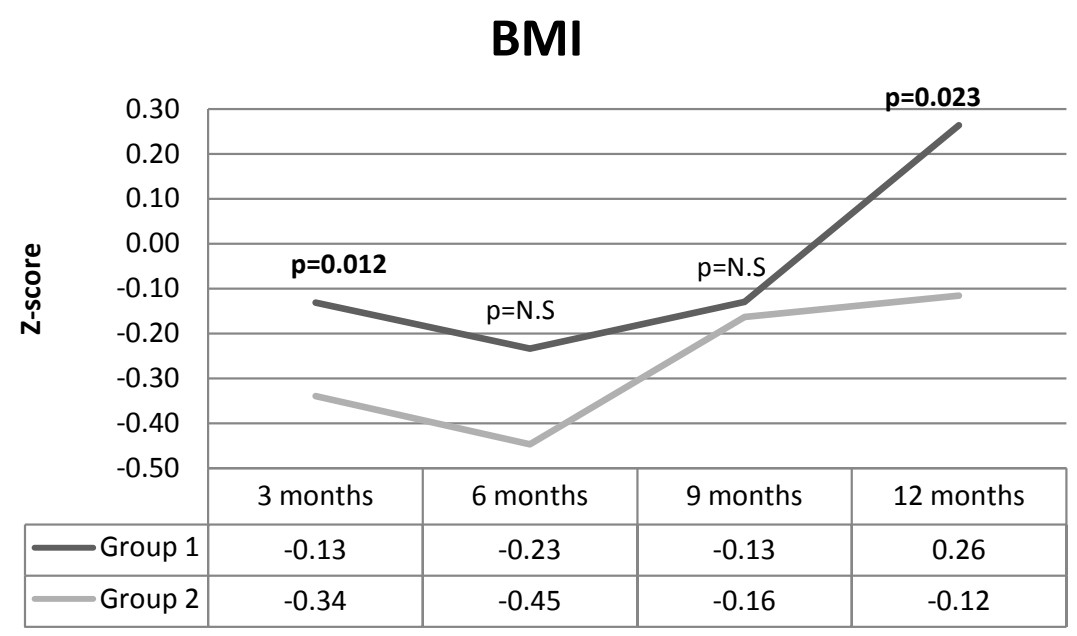

Graphic 4. Average BMI z score change in the two groups from 3 to 12 months.

BMI of the $1^{\text {st }}$ group had a higher Z-score. These differences were statistically significant for the weight and length of 6-month-olds and for the BMI of 3- and 6-month-olds.

\section{Discussion}

The increasing survival of very low birth weight infant is still currently a challenge for the full medical team. As reported by some authors, "the chief variable in determining the weight curve of premature infant is the feeding policy" [6]. We conducted this study to determine postnatal growth in response to current nutritional practices and as a first step to improve post natal growth and nutritional status.

Of the total population only $54.5 \%$ started PN on the first day of life. In our Unit it was impossible to institute PN on the first day to all preterm infants who need it because, until now, there were no stock intravenous solutions with proteins.

The achieved maximal doses of proteins were high in preterm under 28 weeks. This was probably because these infants had prolonged PN with minimum enteral nutrition given the possibility to reach higher amounts of liquids, glucose and proteins with parenteral nutrition.

The weight growth of our population in the first 30 days of life (mean of $425 \mathrm{~g}$ ) is according to relevant research literature [7]. VLBW preterm frequently suffers from extra-uterine growth restriction. And in our study, $60 \%$ of the infants were under P10 at 30 day of life, and 63\% of the infants were under P10 at the time of discharge. These results are also similar to what is described in literature [8] [9]. However, these results are far from what is considered ideal, which means that the nutrition given to these infants cannot meet their needs.

This growth restriction observed in the first few weeks of life has consequences in the long term. As observed in Figure 3, 20\% of the infants weighed $<\mathrm{P} 3$ in the $3^{\text {rd }}$ month of corrected age. In the $12^{\text {th }}$ months, only half (10\%) recovered for a higher percentile.

The results of our study evidence the importance of early administration of proteins in the growth of these VLBW infants. The group who started PN on the first day (Group 1) achieved better weight in all periods studied. Another interesting observation was that the infants in the first group had shorter durations of PN administration, earlier start of enteral nutrition, and earlier achievement of full enteral feeding. The group who started parenteral nutrition earlier was also associated with fewer complications (NEC, IVH, sepsis and BPD). Although these data are not sufficient to assume a cause-effect relation, it is well recognized that poor nutrition is associated with more complications [10].

Previous studies have examined the relationship between amino-acid delivery and weight gain [4] [7] [10]. Early administration of amino acids has been shown to be safe, and it promotes nitrogen balance and glucose tolerance in preterm infants [4]. Recent studies support the importance not only of the amount and quality but also of a fast achievement of maximum nutrient levels [3]-[5]. A recent systematic review and meta-analysis [11] show that early PN provides benefit for some short-term growth outcomes with no evidence showing any increase of morbidity or mortality caused by early PN. 
One limitation of the study was that conclusions are drawn on the basis of retrospectively collected data. Another limitation is that it did not evaluate the role of lipids and its influence in the growth of this preterm. Although studied and understood not as much as proteins, fatty acids play a critical role in postnatal brain development [12]. Current recommendations support that, in VLBW, the administration of parenteral amino acids combined with lipids from birth improves conditions for anabolism and growth, which is shown by improved nitrogen balance [13].

Finally it only evaluated growth. It could be argued that growth particularly that of weight might not be the best measure of clinical outcome in nutritional studies in preterm infants. Other criteria such as status of 2-year neurodevelopment or other morbidities may be preferred, especially because of the association between poor growth and these outcomes [14].

\section{Conclusions}

In conclusion, the results of this study, although subject to some limitations, show that the use of early PN is associated with better growth in the first few weeks of life and the first 12 months. Despite the changes in alimentation, it is still difficult to achieve an optimal extra-uterine growth. These facts highlight the importance of studying the underlying causes of postnatal growth failure. Therefore, additional research efforts should be directed to ascertaining the optimum composition and optimum use of PN in preterm infants in order to achieve nutritional strategies that both improve neurodevelopmental outcome and minimize long term metabolic and cardiovascular adverse effects.

Until better strategies arise, early start of the PN is critical. It is essential to maintain better nutritional care. As reported by some studies, adherence to these practices is still not totally ensured [1].

\section{References}

[1] Lapillonne, A., Carnielli, V.P., Embleton, N.D., et al. (2013) Quality of Newborn Care: Adherence to Guidelines for Parenteral Nutrition in Preterm Infants in four European Countries. BMJ, 3, 1-8. http://dx.doi.org/10.1136/bmjopen-2013-003478

[2] Latal-Hajnal, B., von Siebenthal, K., Kovari, H., et al. (2003) Postnatal Growth in VLBW Infants: Significant Association with Neurodevelopmental Outcome. Journal of Pediatrics, 143, 163-170. http://dx.doi.org/10.1067/S0022-3476(03)00243-9

[3] Rigo, J. and Senterre, T. (2013) Intrauterine-Like Growth Rates Can Be Achieved with Premixed Parenteral Nutrition Solution in Preterm Infants. Journal of Nutrition, 143, 2066-2070. http://dx.doi.org/10.3945/jn.113.177006

[4] Sánchez, A.R., Jiménez, R.M.R., Orgaz, M.C.S.G., et al. (2013) Agressive Parenteral Nutrition and Growth Velocity in Preterm Infants. Nutrición Hospitalaria, 38, 2128-2134.

[5] Senterre, T. and Rigo, J. (2013) Parenteral Nutrition in Premature Infants: Practical Aspects to Optimize Postnatal Growth and Development. Archives de Pédiatrie, 20, 986-993. http://dx.doi.org/10.1016/j.arcped.2013.05.021

[6] Dancis, J., O’Connel, J.R. and Holt Jr., L.E. (1948) A Grid for Recording the Weight of Premature Infants. The Journal of Pediatrics, 33, 570-572. http://dx.doi.org/10.1016/S0022-3476(48)80269-6

[7] Garcia, L.V., Erroz, I.O., Freire, M.M., et al. (2012) Does Early Parenteral Protein Intake Improve Extrauterine Growth in Low Birth Weigth Preterm? Anales de pediatria (Barcelona, Spain), 76, 127-132.

[8] Lima, P.A.T., Carvalho, M., Costa, A.C.C., et al. (2014) Variables Associated with Extra Uterine Growth Restriction in Very Low Birth Weight Infants. Jornal de Pediatria (Rio J), 90, 22-27. http://dx.doi.org/10.1016/j.jped.2013.05.007

[9] Clark, R.H., Thomas, P. and Peabody, J. (2003) Extrauterine Growth Restriction Remains a Serious Problem in Prematurely Born Neonates. Pediatrics, 11, 986-990. http://dx.doi.org/10.1542/peds.111.5.986

[10] Valentine, C.J., Fernandez, S., Rogers, L.K., et al. (2009) Early Amino-Acid Administration Improves Preterm Infant Weight. Journal of Perinatology, 29, 428-432. http://dx.doi.org/10.1038/jp.2009.51

[11] Moyses, H.E., Johnson, M.J., Leaf, A.A., et al. (2013) Early Parenteral Nutrition and Growth Outcomes in Preterm Infants: A Systematic Review and Meta-Analysis. The American Journal of Clinical Nutrition, 97, 816-826. http://dx.doi.org/10.3945/ajcn.112.042028

[12] Vlaardingerbroek, H., Vermeulen, M.J., Carnielli, V.P., et al. (2014) Growth and Fatty Acid Profiles of VLBW Infants Receiving a Multicomponent Lipid Emulsion From Birth. Journal of Pediatric Gastroenterology and Nutrition, 58, 417-427. http://dx.doi.org/10.1097/MPG.0000000000000280

[13] Vlaardingerbroek, H., Vermeulen, M.J., Rook, D., et al. (2013) Safety and Efficacy of Early Parenteral Lipid and 
High-Dose Amino Acid Administration to Very Low Birth Weight Infants. Journal of Pediatrics, 163, 638-644. http://dx.doi.org/10.1016/j.jpeds.2013.03.059

[14] Ehrenkranz, R.A., Dusick, A.M., Vohr, B.R., et al. (2006) Growth in the Neonatal Intensive Care Unit Influences Neurodevelopmental and Growth Outcomes of Extremely Low Birth Weight Infants. Pediatrics, 117, 1254-1261. http://dx.doi.org/10.1542/peds.2005-1368

\section{Abbreviations}

BMI: Body Mass Index

BPD: bronchopulmonary dysplasia

GA: Gestational age

IUGR: Intrauterine growth restriction

IVH: Intraventricular hemorrhage

NEC: Necrotizating enterocolitis

PN: Parenteral nutrition

SGA: Small for gestational age

VLBW: Very low birth weight

WHO: World Health Organization 